Proceedings of the 2010 Winter Simulation Conference

B. Johansson, S. Jain, J. Montoya-Torres, J. Hugan, and E. Yücesan, eds.

\title{
NORMATIVE, CULTURAL AND COGNITIVE ASPECTS OF MODELLING POLICIES
}

\author{
Virginia Dignum \\ Technology, Policy and Management \\ Delft University of Technology \\ 2600 GA Delft, THE NETHERLANDS
}

\author{
Frank Dignum \\ Information and Computing Sciences \\ Utrecht University \\ 3508 TB Utrecht, THE NETHERLANDS
}

\author{
Sjoukje A. Osinga \\ Gert Jan Hofstede \\ Logistics, Decision and Information Sciences \\ Wageningen University; Social Sciences Group \\ 6706 KN Wageningen, THE NETHERLANDS
}

\begin{abstract}
Effective support for policy makers depends on the ability to model the micro level, in terms of adaptive individual decision making process given subjective social norms, individual preferences, and interpretation of policies. But also requires the specification of macro level changes such as institutions and emerging norms and values. In this paper, we introduce the MASQ metamodel to describe both the macro as well as the micro level issues that relate to policy evaluation, and their interactions. We use a real life scenario, on the pig farm industry in China, to illustrate our proposal.
\end{abstract}

\section{INTRODUCTION}

Effective support for policy makers depends on the ability to model the adaptive individual decision making process given subjective social norms, individual preferences, and interpretation of policies (Grothmann and Patt 2005). The development of policies is based on aggregate top-down assumptions of economic behavior, whereas many changes occur due to bottom-up behavior that cannot easily be predicted from aggregate characteristics. Changes at population level are due, on the one hand, to the degree of capacity for adaptation of a population and, on the other hand, to cultural drift, the random cultural change of societies (Bainbridge 1984). These circumstances make the process of introducing new public policies very complex, in the sense that the behavior of society at the macro-level depends directly on the individual behavior of the people in that society and ongoing dynamics of the environment. It is at the microlevel that change is initiated, that policies effectively change the behavior of individuals.

Due to the heterogeneity of societies and groups, changes may occur that were not foreseen at the introduction of a policy, leading to a low efficacy of a policy, if anything is achieved at all. Kable and Glimcher have shown that social norms vary from culture to culture (Kable and Glimcher 2007). Moreover, social norms have measurable consequences for the environment, e.g. energy intensive consumerism and lifestyles, have lead to the ecological near-crisis now at hand (Stern 2006).

To support policy design, it is therefore desirable to evaluate proposed policies with models that are not only based on economically desirable behavior (e.g. macro models, equilibrium theory), but on models that take realistic social interaction and cultural heterogeneity into account (Dignum, Dignum, and Jonker 2009). Models to evaluate policies, should therefore be based on the interactions between complex agents that more realistically simulate human adaptive behavior. Also the environment in which the 


\section{Dignum, Dignum, Osinga and Hofstede}

agents act needs to be represented dynamically, under the assumption that the environment influences the behavior of agents as well. Because of the magnitude of the world to be modeled, aggregation may still be necessary for sake of computational reduction.

The above considerations indicate that the design and analysis of policies is a complex task. Many highly interconnected and unforeseen factors influence the applicability and result of new policies. This makes it hard to evaluate a (new) policy and foresee its implications. Macro-economic models are often fairly simple and founded on the principle of appropriate risk weighted return. System dynamics approaches (Sterman 2000) are often used for this effect and focus on the understanding of overall behavior of complex systems over time (e.g., causal feedback loops, nonlinearity). However, they are not well suited to study the effects on individuals and groups involved. That is, those models do not provide the instruments to evaluate a policy at the micro-level of implementation and are not able to handle uncertain situations. On the other hand, micro-models of individuals and groups, usually based on agent models for emergent global behavior, such as Agent Based Social Simulation (ABSS), don't provide means to specify and regulate normative global restrictions (Macy and Willer 2002, Silverman et al. 2006).

Since macro-models do not suffice, policy design has turned to developing and studying agent-based simulations, i.e., micro-level models. In correspondence with the good scientific practice of parsimony, current ABSS models are based on agents with simple cognitive capabilities. However, the societies being modeled in policy making relate to real people with real needs and personalities, often of a multi-cultural composition. Those circumstances require the agents to be diversified to accommodate these facts.

In this paper, we introduce a model to describe both the macro as well as the micro issues that relate to policy evaluation. We use a real life scenario, on the pig farm industry in China to illustrate our proposal. The paper is organized as follows: in the next section, we introduce a working scenario that will be used throughout the paper to illustrate the different aspects. In section 3, we discuss the necessity to integrate macro and micro levels of decision making, and propose the OperA model as a means for this integration. In section 4, we describe the MASQ metamodel of societies and individuals, and in section 5, we discuss how culture evolves. We present conclusions and directions for future work in section 6 .

\section{SCENARIO: CHINESE PIG FARMERS}

China produces and consumes $50 \%$ of the entire world's pork. The Chinese government has targets and requirements for the pork sector, but the majority of producers are individual farmers who act on their own authority. It is assumed that improving information systems will increase the sector's average product quality. The project described in (Osinga et al. 2010) investigates the supposed link between information provision and product quality, and seeks to find what insights agent-based simulation models can give in the observed discrepancy between the two levels of sectoral information management.

Multiple levels are a characteristic of Chinese society: China's centralized government has the power to implement measures in a relatively short time, in a vertical chain through successively lower levels of government. Responsibilities are person-based rather than rule-based within a multi-layered hierarchical structure (Jahiel 1998). The government has clear targets in these times of economic growth: both pork volume and quality must increase (China 2007). On the other hand, there is a large population of individual pig producers consisting of many farmers who, on average, have a relatively small number of pigs. It is not easy to find a strategy to reach and inform all farmers. Moreover, the individual farmers are heterogeneous: even if all farmers acquire improved information, there is no guarantee that they will act on it, for instance, will adopt the measures brought to them. Decisions are not only based on economic arguments but for a whole variety of reasons, including peer pressure and conformance to authority. Personality traits and cultural attributes influence the decision to act on the received information. In short, and taking the perspective of the pig farmers, the following elements are relevant: 


\section{Dignum, Dignum, Osinga and Hofstede}

- Informing behavior of the government. National policy is implemented at provincial level through county bureaus that send out officials to the villages to inform the farmers in their districts. They inspect, give instruction, and distribute medicines, sometimes with help of veterinary service providers or independent companies.

- Motivations, abilities and actions of farmers. For every decision to change something there is an underlying motivation, related to satisfaction with the current situation. Satisfaction in its turn is related to personality characteristics: it depends on a farmer's personality whether for example a certain income is satisfactory or not. Abilities of a farmer also determine his motivation to change something: some farmers have more skills to get things done than others.

- Business network of farmers. Some farmers have an agreement with a local slaughter with minimal capacity, who sells the meat himself in the same neighbourhood. Others arrange their pigs to be taken to middle-sized slaughterhouses with a capacity of less than 100 pigs per day, whose pigs are sold in the wet markets. Or they deliver to larger slaughterhouses that have contacts with restaurants or local supermarkets. Direct contact with a slaughterhouse is worthwhile for a farmer, because it requires no profit to be earned by an intermediary pork dealer. But not all farmers manage to have these contacts.

- Social network of farmers. Many farmers live in close-knit rural communities: their market linkages are embedded in relationships. They share practices with other farmers, who are often family members or neighbours. Therefore, also their social network plays a role when exchanging information and making decisions.

For the sector as a whole, the aim is to improve total pig quality in all market segments. However, demand varies with respect to specific products and also depends on marketing channel. Certain pork products require high quality pig meat (e.g. cutlets for restaurants), but it is more practical to use lower quality for other pork products (e.g. sausages for the fresh market). Ideally, there is a balance between supply and demand for certain quality. When global demand changes, individual farmers should take decisions in order to adapt.

\section{MULTI LEVEL SIMULATION}

There is increasing recognition of the need for research that links the micro- and macro level dimensions of social behavior. In particular, research on local communities has concentrated primarily on individuals as the causal unit of empirical analysis and theoretical inference, particularly with regard to psychological adjustment. As a consequence, research on communities has tended to neglect two crucial issues: the macro-social determinants of community social organization and the contextual effects of community structure on individual behavior (Sampson 1991). On the other hand, the validation of agent-based computational models and simulation results is done mostly from a macro-level perspective (e.g., organizational performance caused by interactions among individual agents). However, Gilbert claims that "to validate a model completely, it is necessary to confirm that both the macro-level relationships are as expected and the micro-level behaviors are adequate representations of the actors' activity" (Gilbert 2004).

In order to connect macro and micro levels of modeling, in our previous work we have presented a multiple level framework for the modeling of complex social organizations (Dignum 2004). The OperA framework consists of three interrelated models. The macro level, dealing with the performance, structure, and behavior of the whole organization, is described in the Organizational Model (OM). This level describes the macro level and determines the way roles are related with each other, and how role goals and norms are 'passed' between related roles. The agent population as a society, the micro level, is specified independently of the OM as a set of individual, heterogeneous agents possibly developed and owned by different parties. The relation between agent (micro) and organizational (macro) level is specified in a meso level, the Social Model (SM) in terms of social contracts that make explicit the commitments regulating the enactment of roles by individual agents. 
The Social Model describes the arrangements between actors to regulate their relations, tasks, responsibilities, allocation of costs, benefits and risks. This is done in the context and restricted by the OM that defines general regulations that always should be adhered to. Social contracts thus describe the capabilities and responsibilities of an agent within the society. The use of contracts to describe the activity of the system allows, on one hand, for flexibility in the balance between organizational aims (macro concerns) and agent desires (micro concerns) and, on the other hand, for verification of the outcome of the system. Finally, given an agent population for a society, the Interaction Model (IM) describes possible interaction between agents. Once all models have been specified, the characteristics and requirements of the society can be incorporated in the implemented software agents themselves. Agents will thus contain enough information and capabilities to interact with others according to the society specification.

In OperA, the organizational model of a society reflects the requirements of the organization's owners. Agents are seen as autonomous communicative entities that will perform society role(s) as a means to realize their own goals according to their own internal aims and architecture. In contrast, constrained by the organizational design, activity is dependent on the capabilities of actual agents present in the society at a given moment. This means that several agent populations are possible for each organizational model, and the objectives of the society will be achieved in different ways. The characteristics and requirements of the society specified in the society model are then incorporated in the software agents themselves as adequate combinations of perceptual and effectual capacities. Agents will thus contain enough information and capabilities to interact with others according to the society specification.

Although the OperA framework gave a good starting point to model societies from both a macro and micro perspective it does not support the modeling of the internal deliberations and personality of agents and more important does not include the cultural dimensions of society. In the next section we introduce the scenario that we try to model and that illustrates the need of cultural and personality characteristics. In section 4 we introduce the MASQ meta-model. This rich, but general meta-model can be used to structure the components that are needed to model all aspects of the scenario. We show how different parts can be concretely modeled using elements from OperA and then concentrate on the role of culture and culture change as determining factor in this use case.

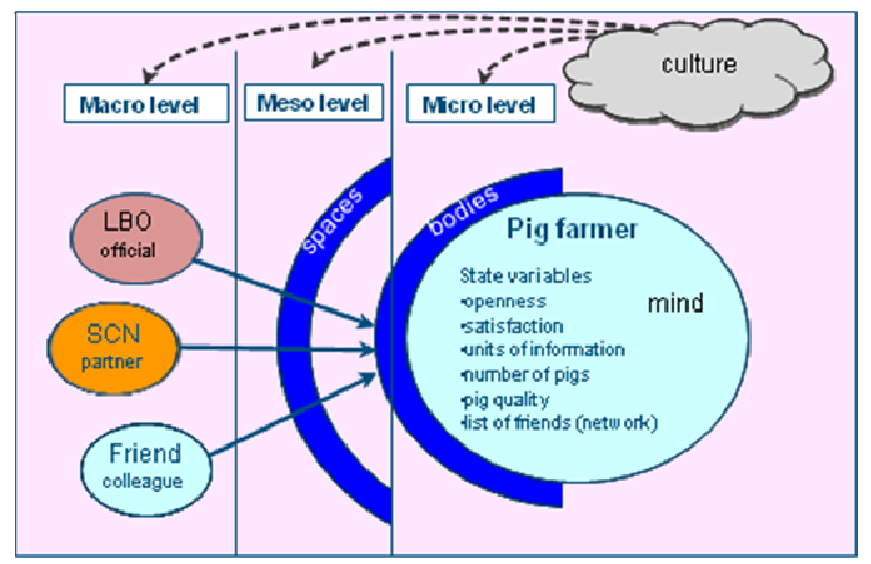

Figure 1: Integrating macro and micro level for the Chinese pig farmer case, from viewpoint of focal farmer.

\section{SIMULATION METAMODEL}

In this section we introduce the MASQ meta-model as a means to structure rich agent based models for simulations. We have developed a micro-macro simulation platform, ABC Lab that supports policy design (Tranier, Dignum, and Dignum 2009). This platform is based on the MASQ meta-model that enables 
the integration of all aspects described above (actors, environment, interaction, organizations and institutions).

\subsection{MASQ Metamodel}

MASQ provides a 4-quadrant framework (Wilber 2001), where the analysis and design of a system is performed along two axes: an interior/exterior axis, and an individual/collective axis. In this section, we introduce the main concepts of the MASQ meta-model. For a more detailed description of MASQ see (Ferber, Stratulat, and Tranier 2009).

Distinguishing between exterior and interior perspective means distinguishing facts (objectivity) and opinions (subjectivity). From the exterior perspective we consider what is observable in the environment (e.g. a behavior exhibited by an agent, a property of an object), whereas from the interior perspective we consider the mental representations about the environment, the decision-making processes, and more generally anything which is a matter of interpretation. The individual/collective distinction is commonly used to analyze complex systems. From an individual point of view, each atomic component of the system is described separately, while from a collective point of view the system is described in terms of the relations who link together all its components and the interactions that occur between them. A 4-quadrant framework consists in the combination of these two axes - interior vs. exterior, and individual vs. collective.

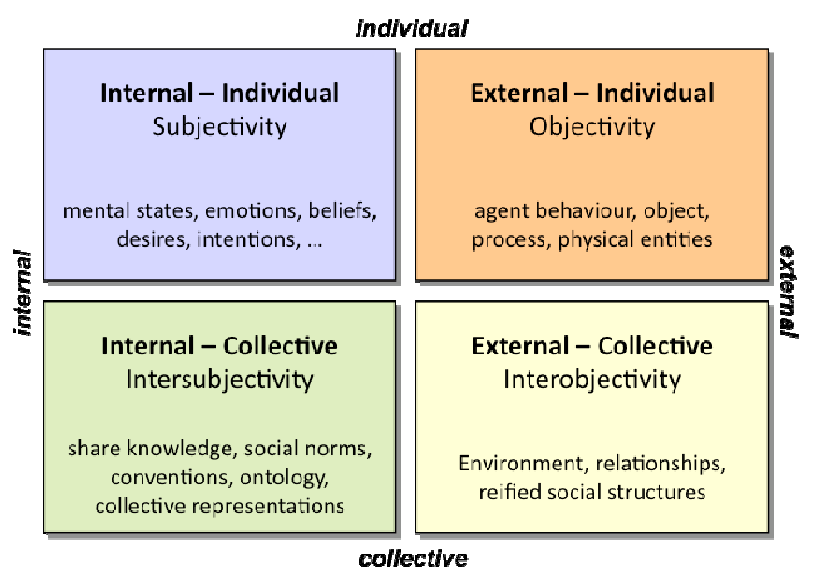

Figure 2: The 4 MASQ quadrants

The MASQ meta-model provides four basic constructs - Mind, Object/Body, Space, Culture - to describe a complex social system, each of them capturing one of the four quadrants.

- Mind. (Interior-Individual) A mind is the internal architecture of an agent, i.e. its decision-making component. The mind is responsible for the behavior selection of the agent (what it intends to do), but not for the behavior execution (what it can do and what it actually does in the environment). This behavior selection takes as input the perceptions of the environment.

- Object/Body. (Exterior-Individual) Objects and bodies are individual entities that compose the environment. They are characterized by a static state which describes their properties (e.g. the dimension of a ball), and a dynamic state which describes their individual activity (e.g. a ball which is rolling). Unlike minds, objects and bodies are neither proactive, nor autonomous. Their evolution is entirely determined by the laws of the environment and the different activities that occur in it. Bodies are special objects that are connected to a mind. A body allows its mind to act on its environment, perceive it and be perceived by other minds. It is the manifestation of an agent in its environment; it allows its very existence in it. A mind does not have an absolute control over its body but influences it. A body then reacts to the received influences according to the laws of the environment. Thus, the body allows for the definition of the action capabilities of an agent within the environment. It also defines the per- 


\section{Dignum, Dignum, Osinga and Hofstede}

ception capabilities of a mind. Bodies don't have to be physical bodies. They can also be defined in terms of speech acts that a mind can use and messages that it can receive.

- Space. (Exterior-Collective) The overall environment is described through several spaces. A space includes objects and bodies, establishes the structure which interconnects it (e.g. a spatial topology, a network, ...), handles the interferences that result from the combination of the individual activities (e.g. a collision between two rolling balls, protocols used between agents) and defines its own dynamics (e.g. gravity). For the agents who have a body within a space, that space represents a specific context for their activities and interactions with the other entities of the space. One agent has a unique mind but may have several bodies in different spaces. Therefore different types of activity can be modeled separately by different spaces, each of them defining a specific structure and a dynamics. Moreover, the concept of space can be used to model both physical and social environments. A social space models specific and deterministic social structures of interaction and contains social bodies, a social body being the manifestation of an agent playing a role.

- Culture. (Interior-Collective) The environment, which is described by spaces and objects, is factual: things are as they are. It constitutes the brute reality in the sense given by (Searle 1997). A culture provides means for a group of individuals to build cultural (or institutional) interpretations of the environment. The interpretation mechanisms provided by a culture are not proper to a single individual, but are shared by a group of individuals. The culture space enables the representation of institutional or organizational facts, such as dependencies, norms and values.

\subsection{Designing Spaces and Bodies}

The exterior perspective of MASQ describes the environment in which agents act. We take an organization-centric view on this external perspective, where interaction is not described in terms of the mental states of individual agents, but in terms of organizational concepts such as roles (or function, or position), groups (or communities), tasks (or activities) and interaction structures.

In this sense, bodies represent roles that individual agents will take, where the enactment of a role contributes to the global aims of the organization. Agents are then seen as actors that perform the role(s) described by the organization design.

In order to support the design of spaces and bodies, we use the OperA modeling framework (Dignum, 2004). In OperA social structures (describing roles and their relationships), interaction structures (describing abstract patterns of interaction and organizational rules and requirements) can be specified. Roles in OperA describe the activities and services necessary to achieve society objectives and enable to abstract from the individuals that will eventually perform the role. In OperA, the definition of a role consists of an identifier, a set of role objectives, possibly sets of sub-objectives per objective, a set of role rights and a set of norms. An example of a role description is presented in Table 1:

Table 1: Role description, representation of a farmer in our scenario

\begin{tabular}{|l|l|}
\hline Role Id & Farmer \\
\hline Objectives & Maximize-farm-profits \\
\hline Sub-objectives & $\{$ healthy-pigs, sell-pigs, optimize-costs \\
\hline Rights & receive-govt-information, talk-to-friends \\
\hline Norms & $\ldots$ \\
\hline
\end{tabular}

Different Minds can fill this description in different ways (e.g. they decide at different times to sell their pigs), but they have a uniform set of objectives, rights and norms that lead their actions in the environment and their interactions with other Minds. 


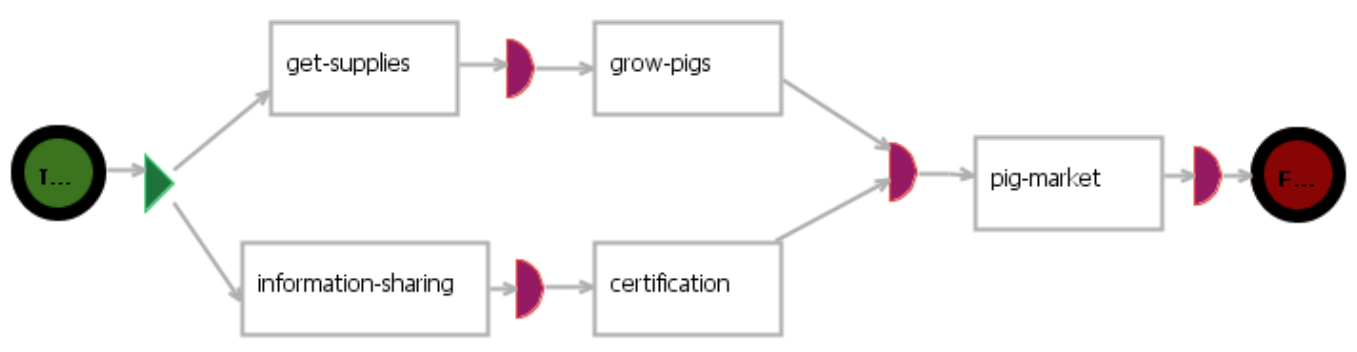

Figure 3: Interaction Structure: workflow of the pig farmers' scenario

The spaces of the MASQ meta-model can be specified using the Interaction Structure of OperA. In OperA, organizational objectives are structured as a set of meaningful scenes that follow pre-defined abstract scene scripts. A scene script describes a scene by its players (roles), its desired results and the norms regulating the interaction. In the OM, scene scripts are specified according to the requirements of the society. The results of an interaction scene are achieved by the joint activity of the participating roles, through the realization of (sub-)objectives of those roles. A scene script establishes also the desired interaction patterns between roles, that is, a desired combination of the (sub-) objectives of the roles. Scenes define different interaction spaces, involving different actors, and are partially ordered into interaction structures as in

Figure 3.

\subsection{Designing Cultures}

The Culture quadrant brings together the subjective norms and values shared by a set of agents and the normative constructs determined by the spaces. The culture quadrant influences both the individual minds, by setting a basis for normative reasoning, and the organizational spaces, resulting in explicit constructs for interaction and dependency. In general cultures define how to determine the value or utility of different situations. Currently we are attempting to provide a computational representation of culture characteristics, based on literature and expert judgment. A thorough and extended process of validation this model of cultures is necessary in future work. Culture includes, at least, the following elements:

- Deontic norms, defined as obligations and prohibitions, indicating desired/required behavior as prescribed by the spaces (e.g. farmers are obliged to provide health reports to officials). These are directly related to the specification of spaces.

- Social norms, that emerge from collective behavior (e.g. farmers share best practices with friends)

- Culture characteristics, defining the 'propensity' of agents along the cultural dimensions defined in (Hofstede and Hofstede, 2005). In particular, we consider

- UAI (Uncertainty Avoidance Index). High UAI increases the defensive threshold against change, and the acceptance of government orders. A high level leads to societies led by deontic norms.

- IDV (Individualism). A high IDV means that agents will follow own goals and beliefs before those of the society (given that they believe that society improves if people act of their own accord and independently).

- PDI (Power Distance Index). A high level means that individuals are more likely to follow norms coming from authorities. High PDI also means that norms can differ by class

- Cultural dimensions have emergent properties when seen in combination. For instance, high UAI and high PDI leads to a pyramid model of organization. The Chinese combination of values is associated with a family model of organization (hence the concept of guanxi, the Chinese form of 'extended business family'). 


\section{Dignum, Dignum, Osinga and Hofstede}

The cultural characteristics may also are reflected in the design of spaces. First of all they might influence the number and separation of spaces. E.g. is there a separation between interactions with friends and interactions with officials and farmers. In a high PDI culture these two spaces might have to be separated, while in a low power distance culture they could possibly be merged. Also, in a high PDI culture the social relation determines the interaction protocols to be used. In high PDI, officials (higher social power) can just order farmers (lower social power) and the order (or information) will be followed. In a low PDI culture, a dialogue between the two is needed that allows for the possibility of argumentation.

\subsection{Designing Minds}

Minds have the ability to determine their own actions, plans and beliefs. From the agent's perspective, its behavior is motivated from their own goals and capabilities and determines the reasons and the specific way an agent will enact its role(s) (Dastani, Dignum, and Dignum 2003). That is, minds bring in their own ways into the environment in the sense that each mind will possible enact its roles differently. We don't presume any agent specification framework here but 'traditional' intelligent agent architectures, such as (versions of) BDI architectures seem the most appropriate. In general it holds that richer architectures give more support to model the deliberation over all the different kinds of elements that influence decision making. But simple models are more efficient in the simulation and work well if the way the elements are combined is predefined and simple to program.

Minds reason about norms and goals depending on their culture and individual preferences. E.g. in low IDV cultures, farmers will take decisions that increase profit for the whole community, high PDI is represented by a low threshold to follow orders by officials, and high UAI means that farmers have an high threshold for risk and consequently are more inclined to follow deontic norms. Following (Dignum, Kinny, and Sonenberg 2002) we use the notation $N_{a} \varphi$ to specify a social norm ('it is normal/it is expected that $a$ will do $\varphi$ ') and $O_{a} \varphi$ to specify a deontic norm (' $a$ is obliged to do $\varphi$ '), $G_{a} \varphi$ to represent that agent $a$ has goal $\varphi, B_{a} \varphi$ to represent beliefs, and the operator $\geq_{a}$ to indicate the relative priorities or preferences the agent $a$ has for different norms and goals. The following are simplified examples of different reasoning rules:

- PDI high: $B_{\text {farmer }} B_{\text {official }} \varphi \rightarrow B_{\text {farmer }} \varphi$

- IDV high: $G_{a} \varphi \quad \geq_{a} O_{a} \rightarrow \varphi$

- UAI high: $O_{a} \varphi \quad \geq_{a} N_{a} \rightarrow \varphi$ (farmer accepts beliefs of officials)

(individual goals are preferred over norms)

(deontic norms are preferred over social norms)

\subsection{MASQ for the Pig Farmers Scenario}

The mind of an agent is its decision making component. Note that elements of mind do not need to be conscious. The agent needs a body to interact with its environment and other agents in it. Interactions occur in a space. Each agent has a different body for each space in which it operates, providing it with interactive capabilities. Spaces can implement normative institutions (e.g. as constraints). Bodies and spaces model limited aspects of physical and social environments. Collective interpretations of the environment are the shared culture of the group, which includes their agreed governance structures. This culture is not necessarily the same as that in the mind of the agents but is influenced by each other.

In the initial version of pig farmers simulation, we distinguish two different types of agents: farmers and government officials. Farmers and officials interact in the information-space. Farmers also interact with other farmers in the friends-space. The physical environment, where farmers interact with their pigs, is represented by the farm-space. The culture of each space is reflected in the shared norms for that space. Farmers' minds contain the following modules: 
- Beliefs, including its perceptions of the world

- Goals, which is this case is to maximize profit by selling its pigs.

- Planning rules, that determine its actions

- Personality. Including its threshold to act on information received from friends and officials

In the in information-space, officials provide information to farmers, introducing them to government policies on pig welfare and farming quality. Farmers give feedback on the usefulness of the information to the officials. The overall objective for this space is to have all farmers know the best suitable practices to raise pigs for their situation. In the friends-space, farmers want to socialize. This can be done by exchanging information about others, but also by discussing best-practices with each other and deliberate on the collective approach to government policies In both the information-space as well as in the friendsspace rules of encounter are given: describing the communication protocols (e.g. in the informationspace, communication is always initiated by the officials). In the farm-space, farmers put their decisions into practice, e.g. feeding methods, buy and sell decisions, health interventions. In Culture, the following elements are represented:

- Norms: farmers are obliged to provide health reports to officials (which is an imposed norm). An emerged norm might be that farmers share information with their friends

- Culture characteristics: In a collectivist culture like in China, farmers take decisions that increase profit for the whole community, the large power distance is represented by a low threshold to follow orders by officials, and uncertainty avoidance means that farmers have and high threshold for risk (i.e. avoid actions of which they cannot directly evaluate the consequences).

\section{CULTURAL CHANGE THROUGH NORM CHANGE}

The MASQ metamodel assumes a close interconnection between the individual its environment (where many other individuals co-exist). This reflects the fact that neither individual behavior nor decisions happen in a void, they happen in contexts: a personal history, an environment, a social setting, (Axelrod, 1984, Einhorn and Hogarth, 1981). The many groups one belongs to contribute to shape one's decisions. These contexts constrain individuals' behavior in important ways to enable social interaction; they establish norms of behavior (Greif, 1994). Norms shape our preferences through a process of cultural learning which is a context and group dependent dynamic procedure (Hayakawa, 2000). But what exactly are the mechanisms and influences underlying norm adoption and change?

Two kinds of norms can be distinguished. First, norms can be implemented through authority, i.e. they are imposed, top-down. We call these institutional norms. These norms are intentional, deliberate external constraints. Second, norms can emerge from the interactions of agents with each other, i.e. bottomup. We call these social norms. The social interactions from which social norms emerge have a certain structure; there are friendships, power relationships, flighty encounters, hero worship and family ties. The social networks an agent belong to, its position in these and the properties of the networks themselves, for example whether they are steep hierarchies or loose connections of equals, will influence the emergence and evolution of social norms and the adoption and internalization of institutional norms (Ajzen and Fishbein 1980; Friedkin 2001).

\subsection{Static and Dynamic Models}

MASQ can be seen in two different ways: (1) as a design tool to describe societies and their participants, or (2) as a simulation environment displaying emergent changing behavior. In the first case, links between the different quadrants are fixed and effect of action does not propagate across quadrants. That is, the rules of the game are fixed for the whole duration of the system. On the latter case, interfaces between quadrants enable change to propagate. E.g. if many farmers Minds have the belief that pigs should only be fed in the morning, that will eventually become a shared social norm. 


\section{Dignum, Dignum, Osinga and Hofstede}

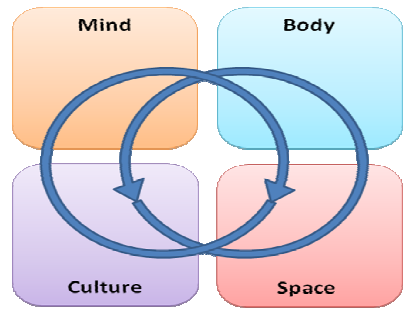

Figure 4: Modeling change in MASQ

Evolution of the system can also be seen in different ways, as depicted in figure 3. For instance, starting from the culture quadrant, (1) changes in culture will lead to changed individual behavior that can eventually lead to changes in the environment, or (2) changes in culture will be enforced in spaces as institutional norms, which lead to different interactions, and eventually to changes in individual behavior. Minds can also influence the Culture, e.g. shared beliefs generate new norms; or the Space quadrant, e.g. changes in goals generate new capabilities that result in new interactions in spaces. Finally, institutional change (in Space or Body quadrants) can lead to changes in minds, e.g. new capabilities and/or constraints for the Bodies lead to new goals for Minds; or to changes in Culture, e.g. new capabilities and/or constraints lead to new norms.

In this dynamic perspective, we should consider norms from two perspectives, the norms that emerged from the actions of the agents and the imposed norms that are put into place to safeguard some properties of the system as a whole. The main difference between these two types in terms of the MASQ model is that the emerged norms do influence the individual decision process of the agents. However, they do not necessarily have an implementation in the spaces. The imposed norms can be seen as forming institutions in the sense of North (1990). They are an abstract specification of the rules of the game. These norms are implemented through constraints and other mechanisms in the spaces. E.g. the norm that a farmer should provide a health report to an official can be implemented into the information space through a trigger that indicates the farmer to submit a report, or through a mechanism that takes care that an official only provides information if it received the health report, or through a monitoring agent that checks if the health report is sent and if not gives a fine. Of course the imposed norms also influence the agent's decisions. If a farmer knows it should send a health report it can take this into account while planning its activities (either fulfilling the norm or violating it).

\subsection{Changing Norms}

Institutional norms can be implemented in different ways, as constraints or as regulations. Representing a norm as a constraint means that there are 'artifacts' in the interaction space that make compliance to the norm unavoidable (e.g. iron gates at the entrance of a metro station), while that using a regulative implementation usually requires that the agents reason about the violation of the norm. Regulative norms are represented in MASQ in the Culture quadrant with a direct link to the Space quadrant, indicating the sanction and monitoring mechanisms determined by the institution.

Institutional norms can be changed by decree. For example norms on animal health and wellbeing have changed radically over the past century. These changes have been enshrined in law, stating that maltreating animals is unacceptable. The norm has now been largely accepted whereas others, such as not using mobile phones in cars, are enshrined in law but hardly anyone seems to follow the institutional norm.

Social norms are the result of individual behavior (repeated and imitated behavior). In most cases, compliance and sanction are not explicitly described in the interaction space, but may have representation in social spaces. Changing social norms is therefore dependent on changes in individual behavior. The more individuals came to follow a certain behavior, the stronger that behavior will become a norm. The ones not following that pattern will be 'looked down' or isolated by the majority. E.g. if most pig farmers believe that pigs should be fed in the morning, the more likely they will take that as a norm, and ones not doing it that way will be pressured to change their behavior. This norm also influences behavior in other 


\section{Dignum, Dignum, Osinga and Hofstede}

ways, e.g. it will not be likely that government officials will call a meeting in the morning because they assume farmers are busy.

Evidence shows that an institutional norm is most effectively implemented if it is supported by social norms (Licht, 2005), but there is a continuous interaction between the two kinds of norms. In the case where social and institutional norms are aligned they are supporting a value that is shared in that society. The increasing acceptance of and compliance to an institutional norm of non-smoking is the cumulative result of a change in the social norm of smoking. For example, when introducing policy prohibiting pigs to be fed antibiotics, an existing social norm on animal health will make it possible to have an institutional ban on antibiotics which, in turn, further will influence the social norm.

\section{CONCLUSIONS}

In this paper we have set out a preliminary framework for simulation support for policy making. We argue that such a simulation tool needs to combine both macro and micro-level models. We presented the MASQ model to describe macro-micro connections. We argue that culture is an integral part of the integration of macro and micro level. We showed how culture is a mix between, on the one hand, emerging phenomena like social norms, and, on the other hand, institutional decisions like laws and regulations. We used the Chinese pig farmers' scenario to illustrate both the specification of the macro-micro model and the way changes occur.

We are currently extending the ideas described in this paper, in applications in different areas including the policies for the introduction of micro-credit and alternative currencies, and business-to-business coordination. Furthermore, we are working on a richer description of culture and individual decision making, specifically on the introduction of values, personality types and reasoning mechanisms.

\section{REFERENCES}

Ajzen, I. and M. Fishbein. 1980. Understanding attitudes and predicting social behavior. New Jersey: Prentice-Hall.

Axelrod, R. 1984. The evolution of cooperation, Basic Books.

Bainbridge, W. 1984. Computer Simulation of Cultural Drift: Limitations on Interstellar Colonisation. Journal of the British Interplanetary Society 37: 420-429

China. 2007. White paper: The quality and safety of food in China. In: China Daily, State Council Information Office. http://www.chinadaily.com.cn/bizchina/2007-08/18/content_6032837.htm.

Dastani, M., V. Dignum, and F. Dignum. 2003. Role Assignment in Open Agent Societies. In: Proceedings of $A A M A S^{\prime} 03$, Melbourne, Australia.

Dignum, F., D. Kinny, and L. Sonenberg. 2002. From Desires, Obligations and Norms to Goals. Cognitive Science Quarterly, 2(3-4):407-430.

Dignum, V. 2004. A Model for Organizational Interaction: Based on Agents, Founded in Logic. Ph.D. thesis, Utrecht University, SIKS 2004-01.

Dignum, F., V. Dignum and C. Jonker. 2009. Towards Agents for Policy Making, Multi-Agent-Based Simulation IX, Lecture Notes in Artificial Intelligence 5269, Springer, pp 141-153

Einhorn, H. and R. Hogarth.1981. Behavioral Decision Theory: Processes of Judgment and Choice. Annual Review Psychology 32:53-88.

Ferber, J., T. Stratulat, and J. Tranier. 2009. Towards an integral approach of organizations: the MASQ approach. In: Dignum, V. (Ed.), Multi-agent Systems: Semantics and Dynamics of Organizational Models. IGI Publishers.

Friedkin, N. E. 2001. Norm Formation in Social Influence Networks. Social Neworks 23(3): 167-189.

Gilbert, N. 2004. "Open problems in using agent-based models in industrial and labor dynamics," In R. Leombruni and M. Richiardi (Eds.), Industry and Labor Dynamics: the agent-based computational approach, World Scientific, pp. 401-405.

Greif, A. 1994. Cultural Beliefs and the Organization of Society: A Historical and Theoretical Reflection 


\section{Dignum, Dignum, Osinga and Hofstede}

on Collectivist and Individualist Societies, Journal of Political Economy 102(5): 912-50.

Grothmann, T. and A. Patt. 2005. Adaptive capacity and human cognition: The process of individual adaptation to climate change, Global Environmental Change Part A, 15(3): 199-213.

Hayakawa, H. 2000. Bounded rationality, social and cultural norms, and interdependence via reference groups, Journal of Economic Behavior \& Organization 43(1): 1-34.

Hofstede G. and G.J. Hofstede. 2005. Cultures and Organizations: the Software of the Mind, Third Millenium Edition, McGraw Hill.

Jahiel, A. 1998. The organization of environmental protection in China. China Quarterly 156: 757-787.

Kable, J.W. and P.W. Glimcher. 2007. The neural correlates of subjective value during intertemporal choice. Nat Neuroscience, 10(12):1625-1633.

Licht, A. N. 2005. Social Norms and the Law: A Social Institutional Approach(March 2005). Available at SSRN: http://ssrn.com/abstract=710621 Polity Press.

Macy, M. W. and R. Willer. 2002. From factors to actors. Annual Review of Sociology 28.

North, D. 1990. Institutions, Institutional Change and Economic Performance, Cambridge Univ. Press.

Osinga, S. A., O. Roozmand, M. R. Kramer, and G. J. Hofstede. 2010. An agent-based model of information management in the Chinese pig sector: top-down versus bottom-up. In Wubben, E. et al. (eds.) 9th Wageningen Int. Conf. on Chain and Network Management (WICaNeM 2010), Wageningen Academic Publishers.

Sampson, R. 1991. Linking the Micro- and Macrolevel Dimensions of Community Social Organization. Social Forces, 70(1): 43-64

Searle, J. 1997. The Construction of Social Reality. Free Press.

Silverman, B., M. Johns, J. Cornwell, and K. O'Brien. 2006. Human behavior models for agents in simulators and games: Part i: Enabling science with PMFserv. Presence: Teleoperators and Virtual Environments, 15(2):139-162.

Sterman, J. 2000. Business Dynamics System Thinking and Modeling for a Complex World. McGraw-Hill Higher Education,.

Stern, N. 2006. Review report on the economics of climate change. HM Treasury, Independent Reviews.

Tranier, J., V. Dignum, and F. Dignum. 2009. A Multi-Agent Simulation Framework for the Study of Intermediation, Proc. 6th Conf. of the European Social Simulation Association (ESSA'09).

Wilber, K. 2001. A Theory of Everything: An Integral Vision for Business, Politics, Science and Spirituality, Shambhala.

\section{AUTHOR BIOGRAPHIES}

VIRGINIA DIGNUM is an Assistant Professor at the group Information and Communication Technology, Department Technology, Policy and Management, Delft University of Technology, the Netherlands. She got her PhD in 2004 from the Utrecht University. Previously, she worked for more than 12 years in industry. Dr. Dignum is involved in several European and national projects, has organized many international conference and workshops (including AAMAS'05). Her research interest focus on the social relations between people and intelligent systems and agent-based social simulation and the use of agent organization models as a basis for the simulation of societies and their many facets, including culture, norms and values, and social networks. Her email address is $\langle m \cdot v \cdot d i g n u m e t u d e l f t . n l\rangle$.

SJOUKJE OSINGA is an Assistant Professor at the group Logistics, Decision and Information Sciences, Wageningen University (Social Sciences), the Netherlands. She has been working in the field of knowledge based systems, knowledge representation issues and web technology. She has been focusing mainly on education, also setting up new courses. In 2006, she spent six month sabbatical leave in China, where she studied the pork chain in general and small-scale pig farmers in particular. She is currently working on a $\mathrm{PhD}$ research regarding agent-based models and multi-level information management, with a case study in the Chinese pork sector. Her email address is $\langle$ sjoukje.osinga@wur.nl $>$. 
GERT-JAN HOFSTEDE is an Associate Professor at Wageningen University (Social Sciences) and at Delft University (Man-Machine Interaction), both in the Netherlands. He has a M.Sc. in Biology and a $\mathrm{Ph} . \mathrm{D}$. in Decision Support Systems and has published widely on national and organizational culture, on modeling culture as the unwritten rules of the game in simulation gaming, and on modeling trust, deceit and culture in agent-based simulation models. He is a co-author of the authoritative bestseller "Cultures and Organizations", author of "Exploring Culture: Stories, Exercises and Synthetic Cultures", and a much-demanded keynote speaker in business and academia across the world. He is editor of the international journal "Simulation \& Gaming". His email address is <gertjan. hof stede@wur. nl>.

FRANK DIGNUM is an Associate Professor at the Department of Information and Computing Sciences, Utrecht University, the Netherlands. He received a Ph. D. from the Free University of Amsterdam in 1989. After receiving his Ph.D. he has set up the computing science department of the University of Swaziland. He has published more than 200 papers and several books. He was PC member and PC chair of many workshops and conference around the world. He has also organized several workshops and was the local chair of the biggest agents conference in the world: AAMAS 2005. He was keynote and invited speaker on conferences in countries as diverse as Australia, Mexico, China and the USA. He has also given many tutorials and seminars at international summer schools. His email address is <dignumecs ou . nl>. 